INTELLECTUAL DISABILITY NURSING 
This page intentionally left blank 


\title{
INTELLECTUAL DISABILITY NURSING
}

\section{An Oral History Project}

\author{
BOB GATES \\ The University of West London, England, UK \\ COLIN GRIFFITHS, PAUL KEENAN, \\ SANDRA FLEMING, AND CARMEL DOYLE
}

School of Nursing \& Midwifery, Trinity College Dublin, Ireland

\section{HELEN L. ATHERTON}

The University of Leeds, England, UK

SU MCANELLY

Northumbria University, England, UK

\section{MICHELLE CLEARY}

Muiriosa Foundation, Ireland

\section{PAUL SUTTON}

The University of West London, England, UK

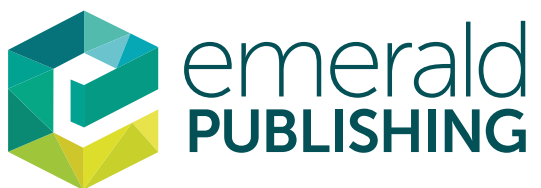

United Kingdom - North America - Japan - India

Malaysia - China 
Emerald Publishing Limited

Howard House, Wagon Lane, Bingley BD16 1WA, UK

First edition 2020

(C) 2020 Emerald Publishing Limited

Reprints and permissions service

Contact: permissions@emeraldinsight.com

No part of this book may be reproduced, stored in a retrieval system, transmitted in any form or by any means electronic, mechanical, photocopying, recording or otherwise without either the prior written permission of the publisher or a licence permitting restricted copying issued in the UK by The Copyright Licensing Agency and in the USA by The Copyright Clearance Center. No responsibility is accepted for the accuracy of information contained in the text, illustrations or advertisements. The opinions expressed in these chapters are not necessarily those of the Author or the publisher.

\section{British Library Cataloguing in Publication Data}

A catalogue record for this book is available from the British Library

ISBN: 978-1-83982-155-4 (Print)

ISBN: 978-1-83982-152-3 (Online)

ISBN: 978-1-83982-154-7 (Epub)

ISOQAR certified Management System, awarded to Emerald for adherence to

Environmental standard 


\section{CONTENTS}

List of Figures and Tables

vii

List of Abbreviations

ix

About the Authors

$x i$

Preface

xiii

Acknowledgements

$x v i i$

Chapter 1 - Intellectual Disability Nursing:

Origins and Contemporary Challenges

Chapter 2 - Background Literature and

Research

Chapter 3 - Method and Methodological Issues

Chapter 4 - Findings

Chapter 5 - Discussion

Chapter 6 - Conclusions, Limitations and Observations 
Appendices

References

Index 207 


\section{LIST OF FIGURES AND TABLES}

\section{FIGURES}

Fig. 2.1. Themes and Factors for an Historical Context of the Vulnerability of Intellectual Disability Nursing in the Jurisdictions of the Republic of Ireland and England.

Plate 2.1. Recruitment Campaign Poster for

Mental Handicap Nursing from the Last Century, United Kingdom.

Fig. 3.1. Verifiable Audit Trail of the Intellectual Disability Nursing Oral History Project.

\section{TABLES}

Table 4.1. Biographical Detail of English Participants.

Table 4.2. Overview of Themes and Categories for England.

Table 4.3. Biographical Detail of Republic of Ireland Participants.

Table 4.4. Overview of Themes and Categories for the Republic of Ireland. 
This page intentionally left blank 


\title{
LIST OF ABBREVIATIONS
}

\author{
ABA - An Bord Altranais \\ BNS - Bachelor of Nursing Sciences \\ BSc - Bachelor of Science \\ $\mathrm{C}$ and $\mathrm{G}-$ City and Guilds
}

CCETSW - Central Council for the Education and Training of Social Work

DOH - Department of Heath

DOHC - Department of Health and Children

EN $(\mathrm{MH})$ - Enrolled Nurse Mental Handicap

EN (MS) - Enrolled Nurse Mental Subnormality

H. Dip. - Higher Diploma

$\mathrm{HE}$ - Higher Education

HEE - Health Education England

HIQA - Health Information and Quality Authority

HSE - Health Service Executive

INMO - Irish Nurses and Midwives Organisation

MA - Master of Arts

NHS - National Health Service

NMBI - Nursing and Midwifery Board of Ireland

NMC - Nursing and Midwifery Council, United Kingdom

NNIDI - Nursing Network in Intellectual Disability Ireland 
NVQ - National Vocational Qualification

PGCE - Post Graduate Certificate in Education

PhD - Doctor of Philosophy

RCN, UK - The Royal College of Nursing, United Kingdom (gained royal patronage in 1939, previously the College of Nursing)

RFN - Registered Fever Nurse

RGN - Registered General Nurse

RMPA - Royal Medico Psychological Association

RNID - Registered Intellectual Disability Nurse

RNLD - Registered Nurse Learning Disabilities

RNMH - Registered Nurse Mental Handicap

RPN - Registered Paediatric Nurse

UKCC - United Kingdom Central Council for Nursing, Midwifery and Heath Visiting 


\section{ABOUT THE AUTHORS}

Bob Gates is semi-retired and works part-time at the University of West London. He is Patron to 'Stanley Grange', and 'Razed Roof'. He has an extensive research and publication record, and in July 2018, he was named as one of 70 of the most influential nurses in the history of the NHS.

Colin Griffiths is a retired Assistant Professor, School of Nursing and Midwifery, Trinity College Dublin, and qualified in intellectual disability nursing. He spent half of his career working with people with intellectual disabilities, and the remainder in Higher Education. His research interests focussed on how people with profound and complex intellectual disabilities communicate.

Helen L. Atherton is a qualified learning disability nurse. She lectures in nursing at the University of Leeds. Her main area of research is the history of people with intellectual disabilities, particularly in relation to eugenic ideas, which was the basis of her $\mathrm{PhD}$. She is a Co-editor of the textbook Learning Disabilities: Towards Inclusion.

Su McAnelly is a qualified Intellectual Disability Nurse, and is now an Associate Professor at the University of Northumbria. She works as an Academic Leader on curriculum development, validation, research, teaching projects and programmes. Her research interests in intellectual disabilities is related to diversity and well-being. 
Paul M. Keenan is an Assistant Professor, School of Nursing and Midwifery, Trinity College Dublin. He has worked in intellectual disability nursing, Higher Education and healthcare management for over 30 years. His research includes person-centred practice and professional nurse development. $\mathrm{He}$ is a Co-Chairperson of Nursing Network in intellectual disability, Ireland.

Sandra Fleming is an Assistant Professor, School of Nursing and Midwifery, Trinity College Dublin. She is qualified in intellectual disability, mental health and general nursing. Currently, she is involved in research projects pertaining to the mental health of people with intellectual disabilities, and supporting adults with intellectual disabilities as they age.

Carmel Doyle is an Assistant Professor in the School of Nursing and Midwifery, Trinity College Dublin. She is qualified in intellectual disabilities and children's nursing. Her research interests are in caring for children with severe and profound intellectual disabilities, and it was in this area that her $\mathrm{PhD}$ work was located.

Michelle Cleary is a Registered Nurse in intellectual disability nursing. She supports teaching at the Centre of Education, Training and Development in the Muiriosa Foundation, Ireland. She teaches across a number of programmes delivered to staff working with individuals with intellectual disabilities.

Paul Sutton is a Fellow at the University of West London. $\mathrm{He}$ is qualified in mental health and intellectual disabilities nursing. He has worked for over 30 years in intellectual disabilities in England and Canada. His research emanating from his $\mathrm{PhD}$ includes resettlement and experiences of mental ill health in people with intellectual disabilities. 


\section{PREFACE}

It is a truism to say that over the last 30 years, intellectual disability nursing has incrementally moved from the narrowly defined roles it occupied within long-term institutional care services to broader roles within a complex landscape of health and social care service provision. Intellectual disability nursing is a specialist part of the wider health care professions occupying a wide portfolio of practice. This specialist part of the wider family of nursing has been supported, endorsed and celebrated by many as unique in its breadth of employment base being located, as it is, among various sectors, and service providers, and is acknowledged in making a valued contribution to the quality of lives of people with intellectual disabilities. The contemporary practice of intellectual disability nursing in England, United Kingdom* has a wide portfolio within services including; community support specialists, liaison posts, hospice care, diversion from custody schemes, epilepsy specialists, secure or forensic health settings, as well as offering a range of specialisms in more generic community nurse roles, and these roles offer support across the age continuum. However, it should be acknowledged that whereas research and policy has supported a clear need for such a range of services in the Republic of Ireland, a diversity of specialist roles has only recently commenced developing as the

\footnotetext{
"Hereinafter we use England only for this jurisdiction save where the use of United Kingdom is suffixed in another specific context.
} 
necessity for change was identified in key policy documents; such roles in the Republic of Ireland include community liaison posts and clinical nurse specialists.

This unique research monograph is based on empirical research which has used the oral history approach to explore the careers of 31 intellectual disability nurses from England and the Republic of Ireland. It reports on our attempt to understand what had motivated these nurses to work in this field of nursing practice, and to learn lessons that might resonate with current nursing workforce challenges, and in particular in the field of intellectual disability nursing. Data were gathered using semi-structured interviews, and digitally recorded. These recordings comprise an important collection now held by the Royal College of Nursing's United Kingdom nursing history archives.

The origins of what was to become the Untold Stories Project, and what was to culminate in this research monograph lay in a bottle of red wine shared in a small village in the Heart of the National Park in the Peak District in the late summer of 2017. Two of the authors, Colin Griffiths and Bob Gates, were reminiscing over their careers, and Colin spoke of his interest in looking back at the careers of a number of nurses in the Republic of Ireland to see if they had experienced the enormity of change that he felt that he had. This was shared by Bob who had a long standing interest in exploring workforce issues in intellectual disability nursing, and he realised Colin's idea would enable him to look at this from a different perspective. The Untold Stories Project, as it was to be called, began to organically form as a viable research project, with an aim and research questions seemingly suggesting the oral history method as the most appropriate research methodological approach to address the questions which began to emerge. The project was called the Untold Stories Project because so little oral historical research has centred on, or has 
been undertaken with intellectual disability nurses; the vast majority of oral history work has focussed on people with intellectual disabilities. At the onset of the project, the College of Nursing, Midwifery and Healthcare, from the University of West London and the School of Nursing and Midwifery, Trinity College Dublin were the two institutions involved in the project. But later on changes to the original personnel involved in the study, along with a need for a more robust research team in England, saw colleagues from the Universities of Leeds and Northumbria join the project.

In the first chapter, we provide a contextualising introduction which culminates in articulating the aim and objectives of the study. This is followed by a chapter that provides a comprehensive background as to the origins of intellectual disability nursing as a workforce, and in particular its precarious positionality within the family of nursing, along with the health and social care workforce more widely. This chapter explores, and in some considerable detail, the interrelated factors which have directly and indirectly contributed to on-going questions as to the vulnerability, and therefore the potential sustainability of intellectual disability nursing in both England, United Kingdom, and the Republic of Ireland. In Chapter 3, we provide a detailed account of the research method employed, and the two subsequent chapters report on findings and provide a detailed discussion, before moving to the concluding chapter of the monograph that presents a series of conclusions, and observations, as well as acknowledging the inherent limitations and strengths of this study.

We offer a note at the outset on terminology that we have adopted in this text. Generally speaking within the United Kingdom, the term 'learning disability' is a descriptive term used to identify, describe and at times categorise people who have significant developmental delay that results in arrested or incomplete achievement of the 'normal' milestones of 
human development. Terms of equivalence used internationally includes: developmental disability, intellectual disability, mental retardation and mental handicap. Notwithstanding this wide array of terminology, and the inappropriateness of some we chose to adopt the term 'intellectual disability' and 'intellectual disability nursing' throughout this book, as we believe they are more universal than that which is used in the United Kingdom, thereby hopefully providing the book with a more universal appeal. Therefore, throughout the text, and from here on in, the term intellectual disability is used; save where certain Acts and/or other technical works require us to use other terms for accuracy.

Finally, we earnestly hope that the many professions and undergraduate students from the wide range of different professional and academic backgrounds that have an interest in historical aspects of the lives of those with intellectual disabilities, and in particular oral history might find this text both interesting and helpful. We also hope that it will be used to promote this specialist field of nursing and recognise the contribution that intellectual disability nurses have made to the lives of people with intellectual disabilities in the past, and the need to sustain this specialist field of nursing practice for the future.

Bob Gates; Colin Griffiths; Helen L. Atherton; Su McAnelly; Paul Keenan; Sandra Fleming; Carmel Doyle; Michelle Cleary and Paul Sutton 


\section{ACKNOWLEDGEMENTS}

There are many people to acknowledge for bringing this project to a successful conclusion: From its original inception by Dr Colin Griffiths, from Trinity College Dublin, through to its publication as a research monograph with Emerald. Firstly, and most importantly, we must acknowledge and thank the participants of this study, 31 intellectual disability nurses, who without their generosity of time, and sharing their oral histories with us this project simply would not have been possible. It was a genuine pleasure and a humbling experience to meet and interview so many talented and inspirational people.

We must also extend our sincere thanks to the Royal College of Nursing, United Kingdom for their invaluable support and expertise in assisting us to archive most of the oral histories of the nurses collected for this study and who are the subject of this monograph. In particular to Teresa Doherty, Joint Head Library and Archive Service, and Royal College of Nursing Professional Lead for History of Nursing, London and Fiona Bourne, Archives Operational Manager, Library \& Archives Service, Royal College of Nursing Archives, Edinburgh. We also owe an enormous debt of gratitude to the Irish Nurses and Midwives Organisation, Republic of Ireland for their very generous financial support for the Irish 'arm' of this study. And in particular to Liam Doran, Former General Secretary, of the Irish Nurses and Midwives Organisation, Dublin. 
Thanks must be recorded to the many reviewers we have encountered on our journey from the very beginnings of this research project with a research proposal. Also to the invaluable help and insights offered by the ethics committees from the Universities of West London and Trinity College Dublin. And heartfelt thanks are due to those who have reviewed the very many abstracts of our work developed for presentations at numerous national and international conferences; this is sometimes a 'thankless task', but we wished to acknowledge these individuals, and the enormity of importance of peer review. Also to our publishers who have been so supportive in seeing our work through to publication.

Finally, there ought to properly be an acknowledgement of the many voices of yesteryear, those who have prepared reports and written papers, as well to the librarians, historians and archivists who have seen fit to archive and preserve their works. Perhaps if we had listened to at least some of them and followed their wise words, we might have learnt something, and we might not be repeating the same mistakes of the past. 


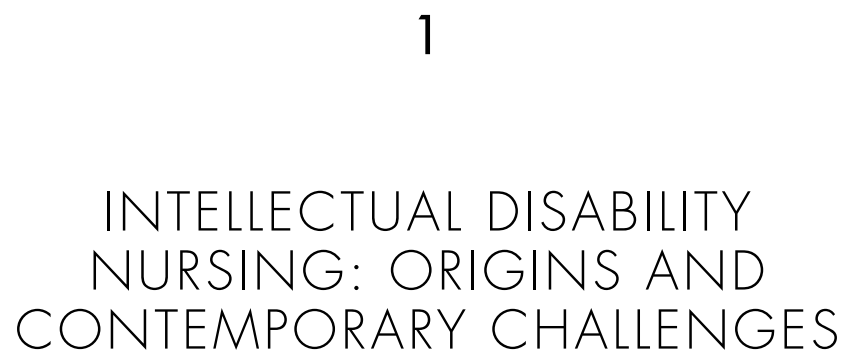

INTRODUCTION

This research monograph concerns itself with the telling of stories. Those stories are of a specialist section of the health care workforce in England and the Republic of Ireland; intellectual disability nurses. ${ }^{1}$ The origins of this workforce can be traced back to a moment in time in the twentieth century, when people with intellectual disabilities were often segregated from their communities in large institutions. Such institutional provision necessitated a specialist workforce that was well educated and trained; intellectual disability nursing was to ultimately emerge to fulfil this role.

Through a series of serendipitous developments during the first half of the twentieth century, intellectual disability nursing became part of the wider nursing family. And as institutions eventually became hospitals, this professional group was considered essential for the effective delivery of medically dominated, psychiatry led regimes of care. However, many decades later, the converse has become the case; instead of being central to the 
delivery of care, the relevance and the specialist contribution of intellectual disability nurses has become the subject of increasing scrutiny, with some considering it now redundant in light of changes to the nature of service provision for people with intellectual disabilities. To date discussion about the future of this professional group has endured unabated; as such their survival as a specialist part of a wider health and social care workforce remains uncertain.

\section{Origins and Contemporary Challenges}

Currently within the United Kingdom of Great Britain and Northern Ireland, and Republic of Ireland, pre-registration undergraduate nursing students choose to follow one of four fields of nursing practice: children, adults, people with intellectual disabilities or mental health. After three or four years of Higher Education and the successful completion of both theoretical and clinical components of a professionally validated programme of study, they are eligible to qualify and register in their chosen specialist field of practice. From an international perspective uniquely the United Kingdom and Republic of Ireland are the only countries to follow this approach (save Hong Kong which retains intellectual disabilities at pre-registration level ${ }^{2}$ ). Instead other countries provide generic pre-registration nurse education, although internationally nurses subsequently do sometimes elect to work with, and support people with intellectual disabilities at the point of post registration.

Intellectual disability nursing itself is a specialist part of the wider health care professions, and it has been supported and endorsed by many as unique in its breadth of employment base being located, as it is, among various sectors, and service providers (Manthorpe et al., Gates, 2011; McCarron 
et al., 2018), and valued for the contribution they make to the lives of people with intellectual disabilities. The contemporary practice of intellectual disability nursing in England has a wide portfolio that includes community support specialists, liaison posts, hospice care, diversion from custody schemes, epilepsy specialists, secure or forensic health settings, as well as offering a range of specialisms in more generic community nurse roles, and these roles offer support across the age continuum (Gates \& Mafuba, 2014; Manthorpe, Alaszewski, Motherby, Gates, \& Ayer, 2004; McCarron et al., 2018). However, it should be acknowledged that whereas research and policy supports a clear need for such a range of services, this diversity of services remains rare or non-existent in the Republic of Ireland (Keenan, 2007; McCarron et al., 2018).

But despite the specialist nature of intellectual disability nursing, and the known contribution they make to the lives of people with intellectual disabilities and their families (Brown et al., 2016; Doody, Slevin, \& Taggart, 2017), the number of these nurses in England has witnessed a vertiginous decline over the last few decades (Gates, 2010; Gates, 2011; Glover \& Emerson, 2012; Health Education England, 2018), making them something of an increasing rarity. In the United Kingdom, the numbers of registered intellectual disability nurses have continued to decrease from 18,546 in 2015 to 17,125 in 2019 - c 8\% reduction (Nursing and Midwifery Council, United Kingdom, 2019). In the Republic of Ireland, the numbers of registered intellectual disability nurses have also decreased from 6,085 in 2016 (An Bord Altranais, 2018), and according to the Communications and Governance Officer to the NMBI to 5,181 in January 2020 - c $15 \%$ reduction (Personal Communication, Communications and Governance Officer to the Nursing and Midwifery Board of Ireland (NMBI), 30/05/2020). Prior to the date parameters used in this monograph, the Republic of Ireland had experienced a 
rapid growth in the numbers of registered intellectual disability nurses, which perhaps might partly be accounted for by the Irish Economic Boom (colloquially known as the Celtic Tiger) that facilitated an expansion of service provision as well as training more intellectual disability nurses to address acute staff shortages (Department of Health and Children, 1998; Humphries, Ruairi Brugha, \& McGee, 2012). These shortages were evidenced by challenges in securing an adequate specialist intellectual disability nursing workforce through local and national recruitment alone. Instead of intellectual disability specialists, service providers had to resort to employing general and children's nurses to deliver the care and support rather than intellectual disability nurses (McGonagle, O'Halloran, \& O'Reilly, 2004); some of these came from countries such as India and the Philippines, and were nurses predominantly trained in the areas of general, mental health and children's nursing (Humphries et al., 2012; McGonagle et al., 2004). Additionally, these shortages also led to the development of new posts for health care assistants, and an emerging workforce of Social Care workers to meet the social care needs of those residing in residential care (Health Service Executive, 2011; Keenan, 2017). Whereas intellectual disability nurses in the Republic of Ireland have developed their inter-professional practice through working with such groups, and by leading and co-ordinating effective care for the benefit of people with intellectual disabilities (McCarron et al., 2018), their ultimate future, as a consequence of these social care workers, remains to be seen. In the United Kingdom more widely, and particularly so in England, the numbers of registered intellectual disability nursing have been falling, and for some time; possibly a decade or more.

One of the difficulties in predicting a future of intellectual disability nursing in the Republic of Ireland could, in part, be due to temporal variance in models of service provision for 
people with intellectual disabilities. In England, and more generally in the United Kingdom, many people with intellectual disabilities now live in either their own homes, or small community settings. This follows a long period, comprising many decades, in which large scale, often segregated institutional health based provision, dependent on a nursing workforce, was gradually phased out in favour of small scale community based provision based on the principles of ordinary living, and supported by a social care sector workforce (Walmsley, 2007; Welshman, 2007). In contrast, the move from congregated to community living in the Republic of Ireland has only more recently begun to take place with contemporary estimates showing that a higher number of residential services still exist there as compared to England, and the United Kingdom more widely, and fewer numbers of people with intellectual disabilities living independently (McConkey \& Craig, 2017; Sheerin, Griffiths, Keenan, \& De Vries, 2015). Perhaps because of the relatively slower pace of change, the effects of changes to service provision on the numbers of intellectual disability nurses in the Republic of Ireland could remain unknown for some time. However, it may not be unreasonable to assume that structural changes to service provision will undoubtedly lead to future questions as to the viability of this specialist field of nursing practice, as has been the case in England, and more widely in the United Kingdom. However, as will be shown later in this monograph, the reasons attributed to the vulnerability of intellectual disability nursing are far more complex than just the changing nature of services.

Such vulnerability of a specialist part of the wider nursing workforce being perceived as redundant is not without precedence. Currie (2005) has provided a parallel historical account concerning the rise, and then subsequent fall of Registered Fever Nurses (United Kingdom), or Registered Infectious Disease Nurses (Ireland). This now vanished specialist part of 
the nursing workforce was in the past needed to run the fever hospitals of the nineteenth and twentieth centuries established to care for patients with a range of communicable diseases of a bygone age. However, as a consequence of medical advances and treatment regimens, such hospitals were no longer thought necessary, and all were to eventually close in the twentieth century. Consequently, the fever registers closed, and this specialist field of nursing practice was relegated to the annals of history. The point being made here is that this specialist workforce was inextricably linked to the physicality of the buildings as legitimising their role along with the continuing necessity of such a specialist workforce. This said in the context of service reconfigurations for people with intellectual disabilities these are but one small part of a much larger and complex range of factors that have contributed to the vulnerability of intellectual disability nursing as a necessary workforce, that have given rise to ongoing questions about its sustainability as a specialist field of nursing practice. These factors emanate from both within and outside of the nursing profession, and can be portrayed at the level of the individual, the profession, government and society in general, and as will be shown in the subsequent chapter it is the complexity of this interplay between these different levels, as located along a temporal continuum, that may account for the situation that intellectual disability nursing now finds itself in, particularly so in England. Yet despite this uncertainty as a profession, it still continues to attract to, and retain a dedicated, albeit, increasingly smaller workforce (UK Chief Nursing Officers, 2012).

Notwithstanding in both jurisdictions, intellectual disability nursing numerically remains one of the smallest of the four fields of nursing practice, and its gradual decline as a workforce, particularly in England, has resulted in them facing uncertainty as a viable future specialist health workforce; this in turn will have significant implications for the 
implementation of national policies affecting the lives of those with intellectual disabilities (Health Education England, 2018; Merrifield, 2018; National Health Service, 2018).

Little research exists as to why individuals are attracted to a field of nursing practice whose existence is, at best, precarious. Indeed, an initial scoping review of published literature undertaken in preparation for this current study found scant evidence on the subject. Whereas personal stories of people with intellectual disabilities appear to have received considerable attention from the academic community there are, by way of contrast, few authentic historical accounts of the lived experience of intellectual disability nurses. And of those that have been published (Gates \& Moore, 2002; Mitchell \& Chapman, 2008; Mitchell \& Rafferty, 2005), factors affecting their motivation to remain in the profession have not been explicitly explored. In studies where individual motivations for entering and remaining in the profession have been considered (Genders \& Brown, 2014; Owen \& Standen, 2007), there appears no comprehensive account of them. Moreover, the possibility of international differences has not, as of yet, been acknowledged or studied. In the Republic of Ireland, specifically there exists limited empirical, or in-depth contextual analysis of the history of intellectual disability nursing (Sweeney, 2003, 2011); this makes a study such as this both timely and perhaps long overdue.

Thus, this monograph reports on a unique study that has sought to contribute to an area of nursing research, where there is limited knowledge and understanding and to address this through employing the oral history method to capture the personal accounts of intellectual disability nurses with over 30 years' experience in this field of practice. It analyses these stories to try and understand the individual motivations of these staff for, not only, entering the profession, but also choosing to spend so much of their working life, in some 
cases all of their working life employed in the care of people with intellectual disabilities. It also seeks to learn lessons that might resonate with the current crises in nursing recruitment, and retention in nursing specialities, particularly intellectual disability nursing, specifically in Republic of Ireland and England. The project has sought to accomplish the preservation of these stories in a unique collection now held in the Royal College of Nursing's history archive in Scotland, United Kingdom in order for nursing, social science or history scholars of the future to have access to data that ordinarily would have been at risk of being lost forever. Because of the almost complete closure of intellectual disability hospitals in both jurisdictions, and the accompanying move away from congregated living, few, if any, of the remaining practising intellectual disabilities nurses will have had experience or knowledge that is located in the old 'long stay' institutions. It was therefore also timely to undertake this project to give voice to some of the 'untold stories' of intellectual disabilities nurses from these traditional services, along with others who all have worked for many years in other areas of intellectual disability care.

We commence this study from an evidenced, albeit limited, based premise that intellectual disability nurses are considered an essential contributor to the lives of people with intellectual disabilities and the wider health and social care workforce, particularly so the nursing workforce. It might be argued that in an 'ideal world', there would be no need for a specialist intellectual disability workforce as people with intellectual disabilities would have their healthcare needs met by the same services as their non-disabled peers. And whereas closure of the old long stay institutions, along with a shift toward integrated, rather than segregated services has resulted in the majority of people with intellectual disabilities in England, and increasingly so in Republic of Ireland, having their 